\title{
Silicon quantum dot solar cell using top-down approach
}

\author{
Paresh Govind Kale $\cdot$ Chetan Singh Solanki
}

Received: 16 July 2014/ Accepted: 25 December 2014/Published online: 21 January 2015

(C) The Author(s) 2015. This article is published with open access at Springerlink.com

\begin{abstract}
The current trend of research in the area of third-generation photovoltaics is to increase the efficiency of solar cell device adopting alternate and novel ways such as use of quantum dots to absorb maximum solar spectrum. A new and low-cost top-down approach to fabricate silicon quantum dot solar cell (QDSC) using spin coating of $\mathrm{Si}$ QDs embedded in flowable oxide is proposed. Si QDs with diameter smaller than $8 \mathrm{~nm}$ were synthesized using topdown approach by ultrasonication of freestanding porous silicon films obtained by anodization of Si. Systematic measurements of current density-voltage $(J-V)$, capacitance-voltage $(C-V)$ and external quantum efficiency (EQE) were carried out. The QDSC exhibits photovoltaic effect, hysteresis in $C-V$ characteristics and improved $\mathrm{EQE}$ performance in short wavelength as compared with a reference c-Si cell with same structure, but without QD layer. The novelty and simplicity of the QDSC fabrication process make these results important.
\end{abstract}

Keywords Quantum dot solar cell · Porous silicon · Spin coating $\cdot$ Ultrasonication

P. G. Kale $(\bowtie)$

224, Department of Electrical Engineering, NIT Rourkela,

Dist. Sundargarh, Rourkela, Odisha 769 008, India

e-mail: pareshkale@nitrkl.ac.in; paresh.iitb@gmail.com

C. S. Solanki

Department of Energy Science and Engineering, Indian Institute

of Technology Bombay, Powai, Mumbai 400076, India

e-mail: chetanss@iitb.ac.in

\section{Introduction}

Silicon quantum dots (QDs) have attracted a broad interest in a wide field of applications such as Si photonics, nonvolatile memory devices, logic nano-devices and also for the third-generation photovoltaic devices [1,2]. Quantum confinement effect, a feature of QDs, is exhibition of discrete energy level by a nanoparticle smaller than exciton Bohr radius [3]. When Si nanoparticles are spaced sufficiently close together, wave functions of quantum confined carriers in adjacent dots overlap. Overlap allows the formation of superlattice with the confined states smearing out to form a mini-band. For sufficiently broad mini-bands, overlap result in widening of the band gap semiconductor material as the particle size reduces [1]. There exists a correlation between band gap of material and the nanoparticle size. Third-generation solar cells use the concept of the band gap engineering to optimize the use of solar spectrum to overcome Shockley-Queisser limit (32.7\% for single-junction solar cells) [4].

Well-known approaches, bottom-up, top-down and functional, are adopted to fabricate QDs. Out of these methods, bottom-up approach using chemical vapor deposition [1,3] or ion implantation [5] or sputtering [6] etc., is the most widely employed technique. Transport properties of the quantum dot-based device depend on the matrix properties in which the Si QDs are embedded. Tunneling probability depends on barrier height and barrier thickness of the insulating material. The higher the barrier height, lower is the tunneling probability. Lower values of barrier height also allow larger spacing among the neighboring QDs present in the matrix. The matrix, also known as superlattice structure, is embedment of QDs in an insulating material like $\mathrm{SiO}_{2}$ or $\mathrm{Si}_{3} \mathrm{~N}_{4}$ [6] or $\mathrm{SiC}$ [7]. Out of these three, $\mathrm{SiO}_{2}$ is an easy to deposit and well-studied 
insulator. However, $\mathrm{SiO}_{2}$ (barrier height $\sim 9 \mathrm{eV}$ ), compared to $\mathrm{SiC}$ (barrier height $\sim 2.5 \mathrm{eV}$ ) and $\mathrm{Si}_{3} \mathrm{~N}_{4}$ (barrier height $\sim 5.3 \mathrm{eV}$ ), has the highest barrier height. Large value of barrier height reduces the current collection probability and, to compensate reduced current, the matrix requires a larger density of Si QDs embedded $[1,7]$.

\section{Experimentation}

Preliminary results of a simple and alternate method to synthesize $\mathrm{Si}$ QDs in the $\mathrm{SiO}_{2}$ matrix using a 'top-down' approach and later to fabricate quantum dot solar cell (QDSC) are reported. Freestanding porous silicon (PS) films are made by anodization, followed by sonication to obtain Si nanoparticles in powder form [8-10]. Monocrystalline CZ-Si wafers with orientation $\langle 100\rangle$, resistivity of $0.01-0.02 \Omega-\mathrm{cm}$ and thickness of $250 \mu \mathrm{m}$ are used for anodization. Electrolyte used for the anodization is prepared with HF and acetic acid mixed in 1:2 proportions. Freestanding PS structure is obtained by modulation of current density between two levels. The level-1 current density $\left(J_{1}=20 \mathrm{~mA} \mathrm{~cm}^{-2}\right)$ is applied for $300 \mathrm{~s}$, while the level-2 current density $\left(J_{2}=50 \mathrm{~mA} \mathrm{~cm}{ }^{-2}\right)$ is applied for 20 s. Level-2 current density results in PS film separation from the parent substrate [9]. The freestanding PS films so obtained are manually crushed and added to de-ionized water to undergo the ultrasonication process for $6 \mathrm{~h}$ in a $120 \mathrm{~W}$ sonication bath operating at $42 \mathrm{kHz}$ frequency. The sonicated solution is heated at $50{ }^{\circ} \mathrm{C}$ to evaporate the deionized water to obtain Si QDs in powder form.

N-type, 2 in. circular Si wafer with orientation $\langle 100\rangle$ and resistivity 4-7 $\Omega \mathrm{cm}$ acts as substrate (n-layer) for all types of devices mentioned henceforth. The substrate is cleaned with $1 \% \mathrm{HF}$ to remove the $\mathrm{SiO}_{2}$ layer before depositing the layer containing QDs. FOx ${ }^{\circledR}$ flowable oxide (XR 1541-006 as obtained from Dow Corning) is used to obtain $\mathrm{SiO}_{2}$ on curing. Flowable oxide comprises hydrogen silsesquioxane (HSQ) resin in a carrier solvent of methyl isobutyl ketone. HSQ is formulated as $\left(\mathrm{HSiO}_{3 / 2}\right)_{n}$ and has cage-like structure of silicon, hydrogen and oxygen atoms. Flowable oxide is spin coated on the substrate to fabricate the intrinsic layer (i-layer), while flowable oxide mixed with QDs is spin coated to obtain ' $\mathrm{i}(\mathrm{QDs})$ ' layer. The spinning process is the same for obtaining both kinds of i-layer and is carried out in two steps: a first spin of $300 \mathrm{rpm}$ for $3 \mathrm{~s}$ followed by a second spin of 3,000 rpm for $30 \mathrm{~s}$. After spin coating, the device is cured on furnace treatment at $400{ }^{\circ} \mathrm{C}$ for $1 \mathrm{~h}$ in the presence of $\mathrm{N}_{2}$. Curing decreases the number of $\mathrm{Si}-\mathrm{H}$ bonds present in HSQ, turning HSQ into porous hydrogenated silicon oxide having a network structure [11]. This transformation of flowable oxide leads to obtain $\mathrm{SiO}_{2}$, i.e., 'i-layer' and $\mathrm{Si}$ QDs

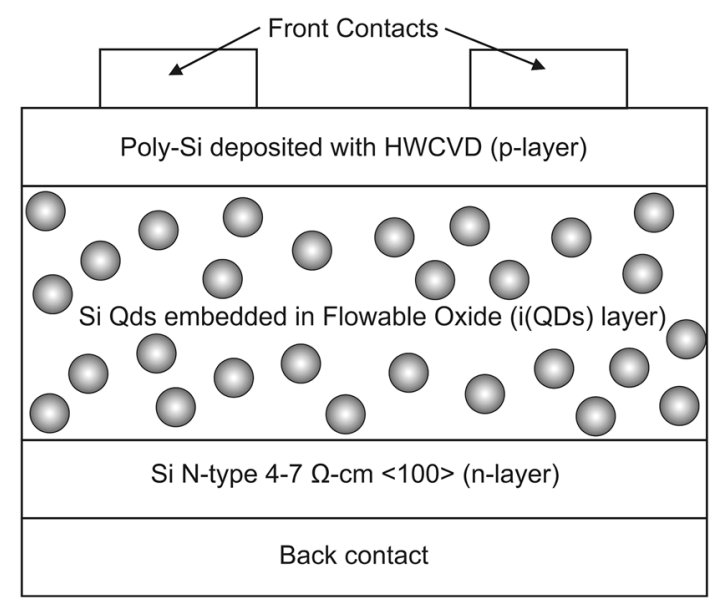

Fig. 1 Schematic of Si QDSC 'n-i(QDs)-p' structure

embedded in $\mathrm{SiO}_{2}$, i.e., ' $\mathrm{i}(\mathrm{QDs})$ ' layer. To complete the QDSC structure, poly-Si layer (p-layer) is deposited using hot wire CVD with substrate temperature of $250{ }^{\circ} \mathrm{C}$ and filament temperature of $1,900{ }^{\circ} \mathrm{C}$ with gas flow rate of $\mathrm{SiH}_{4}: \mathrm{B}_{2} \mathrm{H}_{6}: \mathrm{H}_{2}:: 1: 0.4: 20 \mathrm{sccm}$ maintained for $3 \mathrm{~min}$. Front aluminum contact with $1 \mathrm{~mm}$ diameter using shadow mask and full back Al contact is evaporated using ion beam evaporation. The thickness of the front and back contact is about $100 \mathrm{~nm}$. The whole device is annealed under $\mathrm{N}_{2}$ environment at $400{ }^{\circ} \mathrm{C}$ for $1 \mathrm{~h}$. Four device structures including $n-i, n-p, n-i(Q D s)$ and $n-i(Q D s)-p$ were fabricated to study the role of QDs in QDSC. The ' $n-\mathrm{i}(\mathrm{QDs})-\mathrm{p}$ ' structure, shown in Fig. 1, represents QDSC which is studied for current density versus voltage $(J-V)$ characteristics and external quantum efficiency (EQE) measurement. Capacitance versus voltage $(C-V)$ measurements are carried out on ' $\mathrm{n}-\mathrm{i}$ ' and ' $\mathrm{n}-\mathrm{i}(\mathrm{QDs})$ ' structures to study the charge trapping in Si QDs present in 'i(QDs)' layers. The $J-V$ and EQE of a reference device, ' $\mathrm{n}-\mathrm{p}$ ' structure, is measured and the performance is compared with QDSC.

\section{Results and discussion}

Figure 2 shows cross-sectional high-resolution TEM image of the 'i(QDS)' layer and confirms the presence of crystalline Si QDs with particle size $(d)$ in the range of 3-8 nm embedded in $\mathrm{SiO}_{2}$. The observed particle range represents QDs with energy band gap $\left(E_{\mathrm{g}}\right)$ in the range of $1.34-2.47 \mathrm{eV}$ as calculated using Eq. 1 [3]:

$E_{\mathrm{g}}(\mathrm{eV})=1.16+11.8 d^{-2}$.

Si QDs observed are with non-circular shapes and distinct orientation (Fig. 2) which confirms PS films breakage during sonication to form Si QDs. As measured from highresolution TEM image, the thickness of the coated 'i(QDs)' 
Fig. 2 Cross-sectional highresolution TEM image of 'i(QDS)' layer (thickness $\sim 30 \mathrm{~nm}$ ) on Si substrate. Inset shows an Si QD of $5 \mathrm{~nm}$ diameter

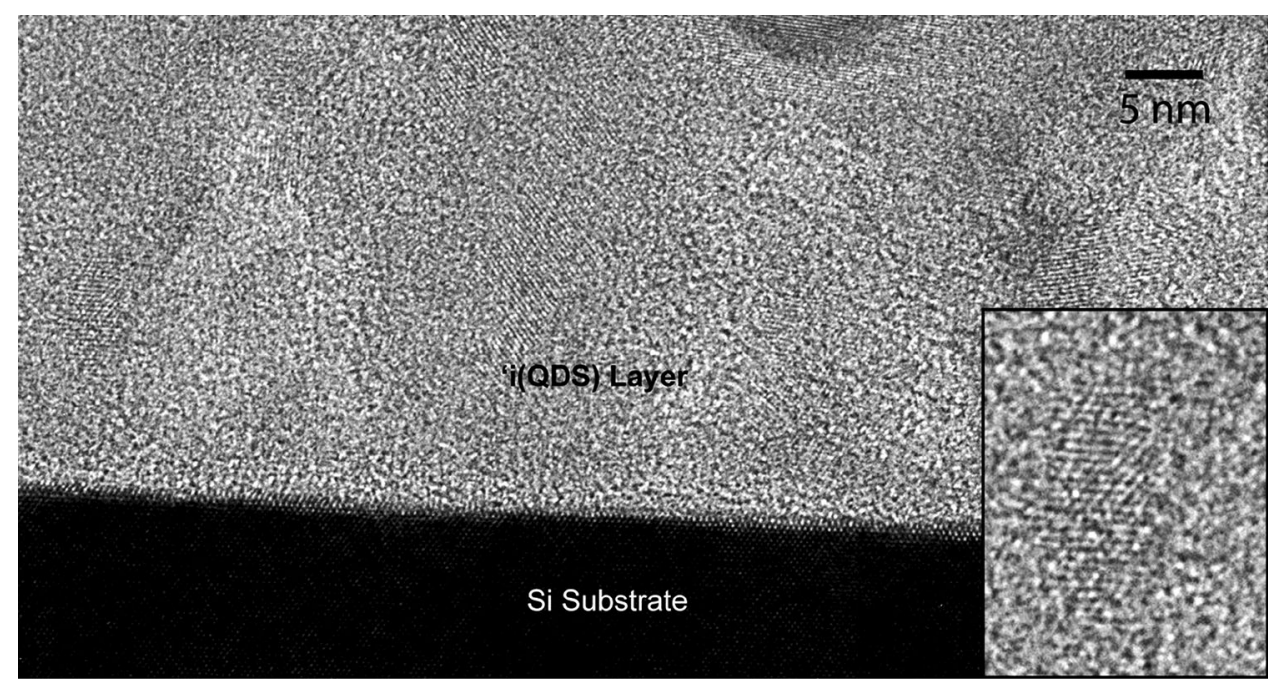

Fig. 3 a Dark, photo and illuminated $J-V$ characteristics of Si QDSC with an area of $1.8 \mathrm{~cm}^{2}$ measured under standard AM 1.5G spectrum, b inset $J-V$ over wide voltage range showing the typical diode-like behavior

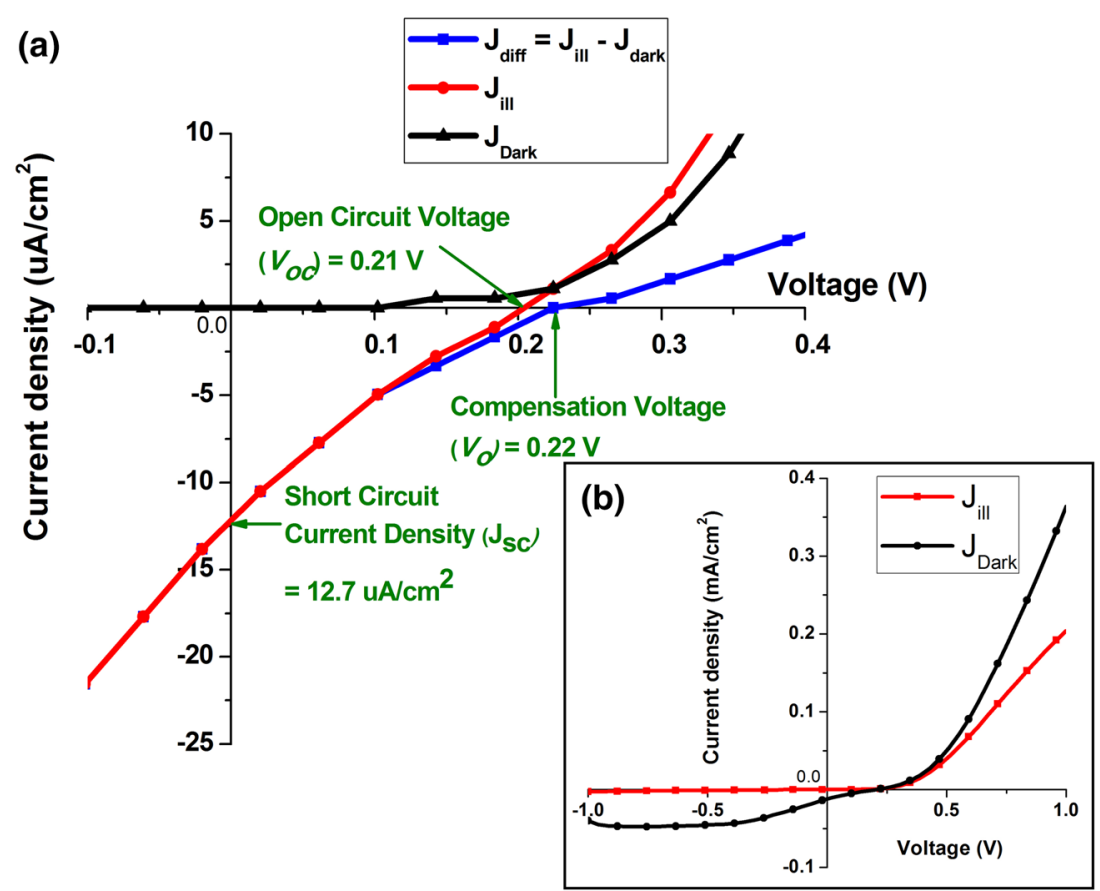

layer is $\sim 30 \mathrm{~nm}$ and the density of the QDs embedded in the layer is $7 \times 10^{12} \# / \mathrm{cm}^{-2}$. The boundaries of the crystallites are ill defined, suggesting surface modification of $\mathrm{Si}$ QD. TEM electron diffraction spectra (not shown here) reassert the surface modification of Si QDs. The source of the surface modification is oxidation of particles during sonication [9].

Photovoltaic properties of QDSC with ' $\mathrm{n}-\mathrm{i}(\mathrm{QDs})-\mathrm{p}$ ' structure are tested under standard test conditions (AM $1.5 \mathrm{G}$ spectrum with illumination level equal to $100 \mathrm{~mW} \mathrm{~cm}^{-2}$ at $298 \mathrm{~K}$ ). As shown in Fig. 3, when illuminated, dark characteristic for QDSC shifts downward confirming the PV properties of the device. QDSC device with area of $1.8 \mathrm{~cm}^{2}$ shows open circuit voltage $\left(V_{\mathrm{oc}}\right)$ of $0.21 \mathrm{~V}$ and short circuit density $\left(J_{\mathrm{sc}}\right)$ of $12.7 \mu \mathrm{A} \mathrm{cm}^{-2}$. The compensating voltage $\left(V_{\mathrm{o}}\right)$ for the solar cell, the voltage where $J_{\text {diff }}$, i.e., difference in $J_{\text {ill }}$ and $J_{\text {dark }}$ becomes zero $[12,13]$, is $0.22 \mathrm{~V}$. According to [6], in QDSC the quasiFermi level splits under light illumination, limiting $V_{\mathrm{oc}}$ of the cell to the band gap of c-Si substrate which is lower as compared to the band gap of Si QDs. Low fill factor (FF) of $21.08 \%$ and the inward bending of illuminated $J-V$ curve in the fourth quadrant could be partly attributed to quasiFermi level splitting. During sonication of PS films, 
hydrogen and oxygen contaminate $\mathrm{Si}$ QDs to produce surface defects [9]. Recombination at oxidized QDs surface is also a suggested reason for low values of $V_{o}$ and $V_{\mathrm{oc}}$ obtained for QDSC [6].

To examine the current transport properties of the QDSC, series resistance $\left(R_{\mathrm{s}}\right)$ of QDSC is estimated from the slope of the linear region of the dark $J-V$ curve at the forward bias voltages between 0.5 and $1 \mathrm{~V}$. Estimated $R_{\mathrm{S}}$ is $1.63 \mathrm{k} \Omega$ and such high value of $R_{\mathrm{S}}$ limits the fill factor and current output from the device. During $J-V$ measurements, single aluminum top contact having an area of $1 \mathrm{~mm}^{2}$ was probed resulting in increased $R_{\mathrm{S}}$ decreasing the current collection. To confirm the effect of $R_{\mathrm{s}}$, top $\mathrm{Al}$ contacts were changed to finger-type Al contact with a total collection area of $14 \mathrm{~mm}^{2}$. With finger-type contact device, $V_{\mathrm{oc}}$ was $0.21 \mathrm{~V}, J_{\mathrm{sc}}$ was
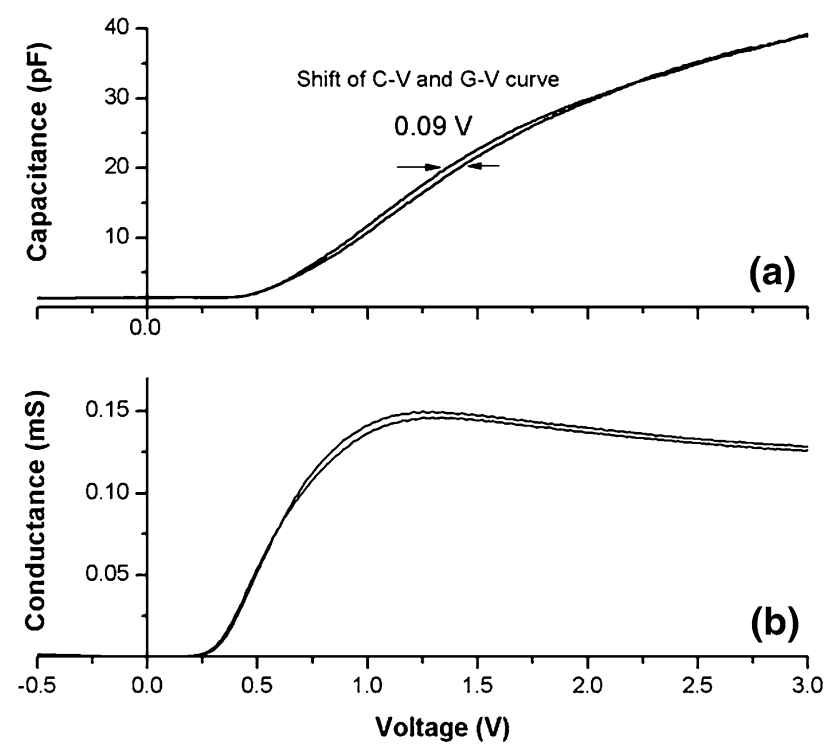

Fig. $4 C-V$ and $G-V$ characteristics of 'n-i(QDs)' structure measured at $500 \mathrm{kHz}$. Curve exhibits a shift of $0.09 \mathrm{~V}$ on the voltage axis
$0.665 \mathrm{~mA} \mathrm{~cm}{ }^{-2}$, FF was $31.4 \%$ and $R_{\mathrm{s}}$ was $31.25 \Omega$. After increasing the top $\mathrm{Al}$ contact area, value of $R_{\mathrm{s}}$ was found decreased, resulting in increase of $J_{\mathrm{sc}}$ and FF value for the cell. The relation of top contact area and cell performance describe the role $R_{\mathrm{s}}$ played in modifying the $J-V$ curve.

$C-V$ and $G-V$ characteristics of ' $\mathrm{n}-\mathrm{i}(\mathrm{QDs})$ ' structure, measured at $500 \mathrm{kHz}$ and swept from -2 to $+2 \mathrm{~V}$, as in Fig. 4, show the charging effect of the $\mathrm{Si}$ nanocrystals embedded in the $\mathrm{SiO}_{2}$ layer. When subjected to dual voltage sweep, the structure exhibits a hysteresis effect in $C-V$ characteristics with a voltage shift of $0.09 \mathrm{~V}$. The presence of electron-occupied sites in the ' $\mathrm{n}-\mathrm{i}(\mathrm{QDs})$ ' structure produces the hysteresis effect. Since the reference sample with ' $n-\mathrm{i}$ ' structure does not reveal any voltage shift, flowable oxide-turned $\mathrm{SiO}_{2}$ creates no traps. The source for hysteresis effect is Si QDs with modified surface and QCE due to presence of Si QDs. The peak seen in the $G-V$ curve appears at the same voltage level where $C-V$ shows a shift, further confirming the cause of shift to be the presence of Si QDs in the ' $\mathrm{i}(\mathrm{QDs})$ layer. The estimated trap or nanocrystal density using voltage shift with Eq. 2 is $6.43 \times 10^{11} \mathrm{~cm}^{-2}$ [14].

$D_{\text {it }}=\left(C_{\text {ox }} / q\right) \Delta V$,

where $\mathrm{C}_{\mathrm{ox}}, q$ and $\Delta V$ are oxide capacitance, elementary charge and voltage shift, respectively. The observed voltage shift is, however, small and attributed to the large inter-QD distance or lower QD density in the ' $\mathrm{i}(\mathrm{QDs})$ ' layer. The $1 / C^{2}$ behavior of the ' $\mathrm{n}-\mathrm{i}(\mathrm{QDs})$ ' structured device, where linear behavior is observed in -0.2 to $0.0 \mathrm{~V}$ range, indicating abrupt junction. The built-in voltage of $0.2 \mathrm{~V}$ is extracted by extrapolating the straight line to the $x$-axis (Mott-Schottky analysis) [15], which is in accordance with the compensation voltage of $0.22 \mathrm{~V}$ obtained using $J-V$ curves.

EQE measurement depicts the contribution of Si QDs in the charge collection in the short wavelength of the light. QDSC is subjected to EQE measurement and is compared with reference device having an ' $n-p$ ' structure. The
Fig. 5 Graph of normalized $\mathrm{EQE}$ for Si QDSC and reference 'n-p' device

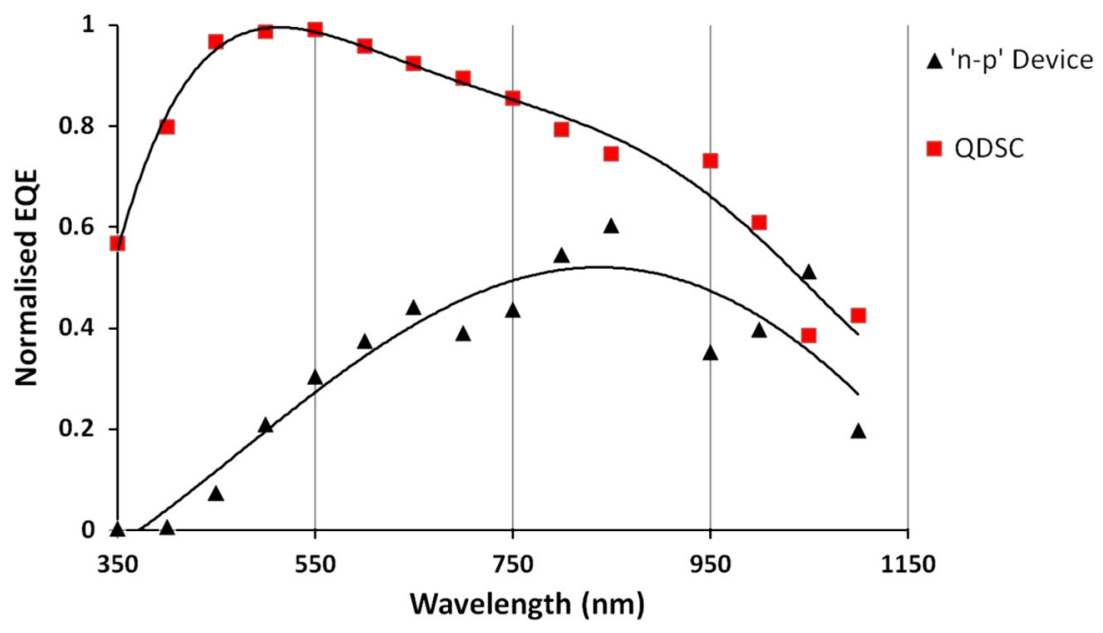


presence of the 'i(QDs) layer' modifies the EQE curve of reference ' $n-p$ ' device as shown in Fig. 5. In the short wavelength range $(400-550 \mathrm{~nm})$ normalized the EQE plot for QDSC which shows the maximum value. Increased $\mathrm{EQE}$ in the shorter-wavelength region is attributed to QCE due to the presence of Si QDs embedded in the 'i(QDs)' layer. In the medium- and long-wavelength range, QDSC shows better quantum efficiency as compared to the reference device. $\mathrm{SiO}_{2}$ present in the 'i(QDs) layer' of the device absorbs medium and long wavelength.

\section{Conclusion}

In conclusion, the use of $\mathrm{Si}$ QDs synthesized on ultrasonication of freestanding PS films with a top-down approach to fabricate QDSC with ' $\mathrm{n}-\mathrm{i}(\mathrm{QDs})-\mathrm{p}$ ' structure was successfully demonstrated. Si QDs mixed in flowable oxide was spin coated and then cured to form the Si QD matrix. The best QDSC device showed photovoltaic effect, $V_{\mathrm{oc}}=0.21 \mathrm{~V}$ and $J_{\mathrm{sc}}=0.665 \mathrm{~mA} \mathrm{~cm}^{-2}$. It is found that series resistance of the device $\left(R_{\mathrm{S}}\right)$ controls the current output and FF of the cell. Quasi-Fermi-level splitting and recombination at oxidized Si QDs surface limits $V_{\text {oc }}$ of the cell. Hysteresis in $C-V$ characteristics and enhanced EQE performance in the short-wavelength range confirms contribution of QDs toward cell performance.

Authors' contributions Dr. PG Kale and Dr. Solanki carried out the study regarding the conceptualisation. Dr. Kale did the design of experiments, carried them out to gather data. He further analysed and interpreted them. Manuscript was drafted by Dr. Kale which was later critically revised by Dr. Solanki.

Open Access This article is distributed under the terms of the Creative Commons Attribution License which permits any use, distribution, and reproduction in any medium, provided the original author(s) and the source are credited.

\section{References}

1. Conniber, G., Green, M., Corkish, R., Cho, Y., Cho, E.-C., Jiang, C.-W., Fangsuwannarak, T., Pink, E., Huang, Y., Puzzer, T., Trupke, T., Richards, B., Shalav, A., Lin, K.-I.: Silicon nanostructures for third generation phtovoltaics solar cells. Thin Solid Films 511-512, 654-662 (2006)
2. Barth, S., Hernandez-Ramirez, F., Holmes, J.D., RomanoRodriguez, A.: Synthesis and applications of one-dimensional semiconductors. Prog. Mater. Sci 55, 563-627 (2010)

3. Kim, T., Park, N., Kim, K.H., Sung, G.Y.: Quantum confinement effect of silicon nanocrystals in situ grown silicon nitride films. Appl. Phys. Lett. 85, 5355-5357 (2004)

4. Shockley, W., Queisser, H.J.: Detailed balance limit of efficiency of p-n junction solar cells. J. Appl. Phys. 32, 510-520 (1961)

5. Yedji, M., Demarche, J., Terwagne, G., Delamare, R., Flandre, D., Barba, D., Koshel, D., Ross, G.G.: Method for fabricating third generation photovoltaics cells based on Si quantum dots using ion implantation into $\mathrm{SiO}_{2}$. J. Appl. Phys. 109(8), 084337 (2011). doi:10.1063/1.3575325

6. Di, D., Heli, X., Ivan, P.-W., Green, M.A., Conibeer, G.: Improved nanocrystal formation, quantum confinement and carrier transport properties of doped Si quantum dot superlattices for third generation photovoltaics. Prog. Photovolt. Res. Appl. (2011). doi:10.1002/pip.1230

7. Kim, T., Huh, C., Choi, C., Suemitsu, M.: In situ-grown hexagonal silicon nanocrystals in silicon carbide-based films. Nanoscale Res. Lett. 7, 634-638 (2012)

8. Kale, P.G., Solanki, C.S.: Synthesis of si nanoparticles from freestanding porous silicon (PS) film using ultrasonication. 35th IEEE Photovoltaic Specialists Conference PVSC 2010, Honolulu, Hawai, 5617016: 3692-3697 (2010)

9. Kale, P.G., Sharma, P., Solanki, C.S.: Synthesis and characterization of $\mathrm{Si}$ nanoparticles obtained on sonication of porous silicon multilayer films. J. Nano res. 17, 13-25 (2012). doi:10.4028/ www.scientific.net/JNanoR.17.13

10. Kale, P.G., Gangal, A.C., Edla, R., Sharma, P.: Investigation of hydrogen storage behavior of silicon nanoparticles. Int. J. Hydrog. Energy 37(4), 3741-3747 (2012). doi:10.1016/j.ijhy dene.2011.04.054

11. Holzwarth, C.W., Barwicz, T., Smith, H.I.: Optimization of hydrogen silsesquioxane for photonic applications. J. Vaccuum Sci. Technol. B25, 2658-2660 (2007)

12. Luther, J.M., Law, M., Beard, M.C., Song, Q., Reese, M.O., Ellingson, R.J., Nozik, A.J.: Schottky solar cells based on colloidal nanocrystal films. Nano Lett. 8, 3488-3492 (2008)

13. Gao, J., Luther, J.M., Semonin, O.E., Ellingson, R.J., Nozik, A.J., Beard, M.C.: Quantum dot size dependant J-V characteristics in heterojunction $\mathrm{ZnO} / \mathrm{PbS}$ quantum dot solar cells. Nano Lett. 11, 1002-1008 (2011)

14. Kim, Y., Park, K.H., Chung, T.H., Bark, H.J., Yel, J., Choi, W.C., Kim, E.K., Lee, J.W., Lee, J.Y.: Ultralarge capacitance-voltage hysteresis and charge retention characteristics in metal oxide semiconductor structure containing nanocrystals deposited by ion-beam-assisted electron beam deposition. Appl. Phys. Lett. 78, 934-937 (2001)

15. Park, S., Cho, E., Song, D., Conniber, G., Green, M.A.: n-Type silicon quantum dots and p-type crystalline silicon heteroface solar cells. Sol. Energy Mater. Sol. Cells 93, 684-690 (2009) 